\title{
Modelling chemistry over the Dead Sea: bromine and ozone chemistry
}

\author{
L. Smoydzin ${ }^{1, *}$ and R. von Glasow ${ }^{1}$ \\ ${ }^{1}$ School of Environmental Sciences, University of East Anglia, Norwich, UK \\ *now at: Max-Planck-Institute for Chemistry, Department of Atmospheric Chemistry, P. O. Box 3060, 55020 Mainz, Germany
}

Received: 22 December 2008 - Published in Atmos. Chem. Phys. Discuss.: 23 February 2009

Revised: 29 June 2009 - Accepted: 23 July 2009 - Published: 28 July 2009

\begin{abstract}
Measurements of $\mathrm{O}_{3}$ and $\mathrm{BrO}$ concentrations over the Dead Sea indicate that Ozone Depletion Events (ODEs), widely known to happen in polar regions, are also occuring over the Dead Sea due to the very high bromine content of the Dead Sea water. However, we show that $\mathrm{BrO}$ and $\mathrm{O}_{3}$ levels as they are detected cannot solely be explained by high $\mathrm{Br}^{-}$ levels in the Dead Sea water and the release of gas phase halogen species out of sea borne aerosol particles and their conversion to reactive halogen species. It is likely that other sources for reactive halogen compounds are needed to explain the observed concentrations for $\mathrm{BrO}$ and $\mathrm{O}_{3}$. To explain the chemical mechanism taking place over the Dead Sea leading to $\mathrm{BrO}$ levels of several $\mathrm{pmol} / \mathrm{mol}$ we used the one-dimensional model MISTRA which calculates microphysics, meteorology, gas and aerosol phase chemistry. We performed pseudo Lagrangian studies by letting the model column first move over the desert which surrounds the Dead Sea region and then let it move over the Dead Sea itself. To include an additional source for gas phase halogen compounds, gas exchange between the Dead Sea water and the atmosphere is treated explicitly. Model calculations indicate that this process has to be included to explain the measurements.
\end{abstract}

\section{Introduction}

Tropospheric ozone depletion events related to highly active bromine chemistry are widely known to take place in polar

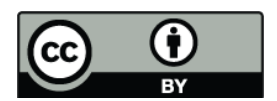

Correspondence to: L. Smoydzin (smoydzin@mpch-mainz.mpg.de) regions and were first observed by Barrie et al. (1988). Several years ago Hebestreit et al. (1999) detected a similar occurrence at the Dead Sea, Israel. Hebestreit et al. (1999) report maximum $\mathrm{BrO}$ mixing ratios of $86 \mathrm{pmol} / \mathrm{mol}$, exceeding even mixing ratios in the Arctic regions. $\mathrm{O}_{3}$ levels dropped simultaneously below the detection limit of $2 \mathrm{nmol} / \mathrm{mol}$. Those first measurements were taken on a peninsula separating the northern and southern part of the Dead Sea. On all measurement days with southerly winds Hebestreit et al. (1999) could observe a strong increase in $\mathrm{BrO}$ mixing ratios until noon. However, no $\mathrm{BrO}$ was found when the wind direction was northerly. Matveev et al. (2001) made $\mathrm{BrO}$ and $\mathrm{O}_{3}$ measurements at the same site as Hebestreit et al. (1999) and obtained similar results regarding the high $\mathrm{BrO}$ mixing ratios but with a maximum of $176 \mathrm{pmol} / \mathrm{mol}$ and correlated $\mathrm{O}_{3}$ depletion events when surface winds were southerly. However, in contrast to the first mentioned measurement campaign they could also detect high $\mathrm{BrO}$ levels when the wind direction was from North to South, even though under those conditions no $\mathrm{O}_{3}$ depletion could be observed. During two long term measurement campaigns, $\mathrm{O}_{3}$ was monitored for more than one year at three sites (South, mid-West, North; additionally at a site $400 \mathrm{~m}$ above sea level on several days). Tas et al. (2003) and Tas et al. (2005) report high levels of $\mathrm{BrO}$ and low levels of $\mathrm{O}_{3}$ on numerous days at all measurement sites, in summer time as well as in winter time. However, aircraft measurements (Matveev et al., 2001) show how strongly variable the horizontal extent of the ODEs are.

A first very simple boxmodel study by Stutz et al. (1999) indicated that the formation of $0.5 \mathrm{nmol} / \mathrm{mol} \mathrm{BrO}$, which is about 3 times the absolute maximum measured $\mathrm{BrO}$ mixing ratio, would be required to destroy an average background level of about $60 \mathrm{nmol} / \mathrm{mol} \mathrm{O}_{3}$ within 2-3 h. A recent model

Published by Copernicus Publications on behalf of the European Geosciences Union. 
study by Tas et al. (2006) tries to explain the high bromine levels observed at the Dead Sea by using a model setup including only the source for gas phase bromine by the release of bromine species from sea salt aerosols which are emitted from the Dead Sea water. They suggest that sea salt aerosols are the predominant source of bromine for the atmosphere above the Dead Sea.

Besides the Dead Sea two other salt lakes have turned out to be regions of highly active halogen chemistry in the midlatitudes. Stutz et al. (2002) could detect BrO mixing ratios of up to $6 \mathrm{pmol} / \mathrm{mol}$ at the Great Salt Lake, USA. The authors find a decrease in $\mathrm{O}_{3}$ mixing ratios simultaneously to the daily $\mathrm{BrO}$ peak period, however, the decrease is far lower than for the Dead Sea. Furthermore, Hönninger et al. (2004) found up to $20 \mathrm{pmol} / \mathrm{mol} \mathrm{BrO}$ correlated with $\mathrm{O}_{3}$ depletion events at the Salar de Uyuni in Bolivia.

\section{Motivation}

Our main scientific objective of this paper is to find an explanation for the measurements taken along the Dead Sea based on a reasonable chemistry mechanism and to reproduce the general features observed at the Dead Sea with a numerical model.

In general the most important source for gas phase halogen species in the marine troposphere are sea salt aerosols. As soon as $\mathrm{H}^{+}$concentrations are large enough, $\mathrm{BrCl}$ and $\mathrm{Br}_{2}$ are formed in the aerosol and degas into the gas phase (Vogt et al., 1996; von Glasow and Crutzen, 2007). Gas phase $\mathrm{BrCl}$ and $\mathrm{Br}_{2}$ are rapidly photolysed during the day and form $\mathrm{Br}$ which can react which $\mathrm{O}_{3}$ and produce $\mathrm{BrO}$. Bromine oxide can react further leading to the production of $\mathrm{HOBr}$. Hypobromous acid is taken up by the aerosol where it takes part in the acid catalysed reactions forming $\mathrm{BrCl}$ and $\mathrm{Br}_{2}$. In addition, $\mathrm{BrO}$ can react with $\mathrm{NO}_{2}$ and produce $\mathrm{BrONO}_{2}$ which participates in heterogeneous reactions on aerosol surfaces also starting the recycling of gas phase species in the aqueous phase (see Fig. 1). It has been suggested several times that due to the very high bromide content and low $\mathrm{pH}$ of the Dead Sea water and thus of emitted sea salt aerosol particles the above explained process leads to extraordinary high $\mathrm{BrO}$ mixing ratios and the related ODEs (Tas et al., 2003, 2005, 2006). Two, very general points speak against this hypothesis (i) The wind speed over the Dead Sea is often low. Hebestreit et al. (1999) and Matveev et al. (2001) report windspeeds of $5 \mathrm{~m} / \mathrm{s}$ and respectively $3 \mathrm{~m} / \mathrm{s}$ which were prevailing during their measurement campaigns where high levels of $\mathrm{BrO}$ were observed. Consequently the number of sea salt aerosol particles that are released from the Dead Sea is low. (ii) As the relative humidity along the Dead Sea valley is often very low (e.g. Alpert et al., 1997, and references therein), aerosol phase chemistry is likely to be of minor importance. A low aerosol liquid water content which consequently has to be the case if ambient relative humidity is extremely low, leads to

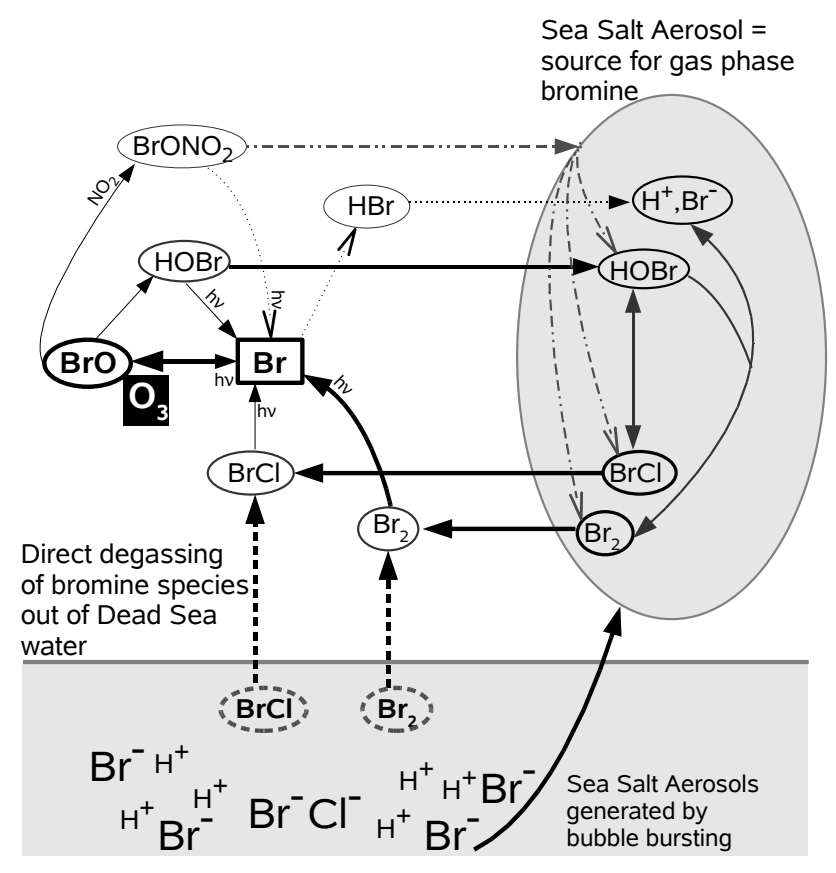

Fig. 1. Simplified overview of the interacting chemistry in the water, the gas phase and aerosol particles.

a slow mass transfer between the aerosol and the gas phase. Thus, only a very limited amount of $\mathrm{BrCl}$ or $\mathrm{Br}_{2}$ can be released out of particles as the total halogen cycling should be weak. Even though freshly emitted sea salt aerosols are deliquescent, it is very likely that these particles dry out quickly.

Furthermore, the analysis of filterable chlorine and bromine from aerosol samples presented by Matveev et al. (2001) suggests that a bromine source in addition to aerosols is needed in order to explain the observations made along the Dead Sea. As the production of $\mathrm{BrCl}$ and $\mathrm{Br}_{2}$ in the aerosol is $\mathrm{pH}$ dependant and the exchange process between the aerosol and the gas phase depends on the solubility of the species as well as their gas phase and aqueous phase concentrations, $\mathrm{BrCl}$ and $\mathrm{Br}_{2}$ can only degas directly out of acidified aerosols but not out of open ocean water with an average $\mathrm{pH}$ of about 8. However, the $\mathrm{pH}$ of Dead Sea water is much lower, leading to larger $\mathrm{BrCl}$ and $\mathrm{Br}_{2}$ production rates in the water. This indicates that beside sea salt aerosols the Dead Sea water itself can be a direct source for gas phase bromine species. In order to investigate this aspect we included the air-sea exchange of bromine species explicitly in a numerical model.

\section{Background information about the Dead Sea}

The Dead Sea extends $75 \mathrm{~km}$ from North to South and $15 \mathrm{~km}$ from East to West. On the East as well as the West shore it is flanked by mountains exceeding $1000 \mathrm{~m}$ altitude. The southern part of the Dead Sea, the so-called evaporation ponds, are 
separated from the northern part by a peninsula. These very shallow basins are fed with water from the northern part of the lake by a channel. The water of the Dead Sea has a very high salinity and acidity compared to ocean water with $\mathrm{pH}$ values in the order of 5 (southern part) to 6 (northern part, Tas et al., 2005). Bromide as well as chloride concentrations increase significantly from the northern to the southern end of the lake $\left(\mathrm{Cl}^{-}: 225-405 \mathrm{~g} / \mathrm{l}, \mathrm{Br}^{-}: 6.1-11 \mathrm{~g} / \mathrm{l}\right.$, Sirkes et al., 1997). Thus the salinity of the water is about 12 times larger than for ocean water which has an average chloride content of about $19 \mathrm{~g} / \mathrm{l}$ and a bromide content of $0.065 \mathrm{~g} / \mathrm{l}$ (Sverdrup et al., 1942).

The topography at the Dead Sea leads to a strongly canalysed wind flow through the valley. The local flow pattern, which is very complex and still insufficiently understood is also partly influenced by the lake breeze (Bitan, 1977; Tas et al., 2003). The wind direction at the North end of the lake is often southerly. The wind direction at the South end seems to be more variable and southerly as well as northerly winds are observed (Tas et al., 2003). As the Dead Sea is surrounded by a desert the temperature is very high with mean values of about $35^{\circ} \mathrm{C}$ in summer and the relative humidity is very low with about 40-50\% (Alpert et al., 1997, and references therein; J. Zingler and M. Piot, Inst. of Env. Physics, Univ. Heidelberg, Germany, personal communication, 2007).

\section{Model description}

For all presented model studies the one dimensional numerical model MISTRA is used. It contains a microphysics scheme and explicitly calculates chemistry in the gas phase, in aerosol particles and cloud droplets (von Glasow et al., 2002a,b). The chemical mechanism contains the most important reactions of $\mathrm{O}, \mathrm{H}, \mathrm{C}, \mathrm{N}, \mathrm{S}, \mathrm{Cl}$ and $\mathrm{Br}$ both in the gas phase and the aerosol phase and has been updated according to the IUPAC recommendation (April 2004, see http: //www.iupac-kinetic.ch.cam.ac.uk). In the model we distinguish between sulphate and sea salt aerosol particles which differ by their size $(r=0.005-0.5 \mu \mathrm{m}$ for sulphate, $r=0.5-$ $15 \mu \mathrm{m}$ for sea salt) and initial chemical composition. The parameterisation of Monahan et al. (1986) for the emission of sea salt particles by bubble bursting is used. An aerosol size distribution for rural areas based on Jaenicke (1988) is used. All presented model runs are set up such that no clouds are formed.

To be able to calculate air-sea exchange between the Dead Sea and the overlying atmosphere, chemistry within the water of the lake is calculated explicitly in addition to the aerosol phase. We assume that the same reaction set which is used for aerosol phase chemistry is also valid for chemistry taking place in the water of the Dead Sea apart from heterogeneous reactions. The only possible interactions that are allowed between the Dead Sea water and the atmosphere is via air-sea exchange of trace gases as is shown exemplarily in Fig. 1. To describe the fluxes of gases across the air-sea interface a two-layer model as first presented by Liss and Slater (1974) is used. The implementation of the air-sea exchange mechanism into MISTRA follows the work done by Pozzer et al. (2006) (and references therein).

For studying the different formation mechanisms of $\mathrm{BrO}$ in detail it is crucial to have a high vertical model resolution. Thus a logarithmically spaced grid for the vertical has been chosen with a grid spacing of $0.5 \mathrm{~m}$ for the lowest grid box above the water surface.

\subsection{Activation of aerosol-chemistry}

Due to the extremely dry conditions along the Dead Sea it is crucial to discuss the way aerosol chemistry is triggered in MISTRA. Aerosol phase chemistry is always calculated if the ambient relative humidity is above the deliquescence humidity of sea salt $(75 \%)$ or sulphate $(70 \%)$ aerosols. When humidity decreases to the crystallisation humidity ( $40 \%$ for sulphate, $42 \%$ for sea salt) calculation of aerosol phase chemistry is terminated. As it can be assumed that freshly emitted sea salt particles are always present as an aqueous solution, sea salt chemistry is always calculated in the lowest model level (over a water surface). As it is well documented that sea salt aerosol particles remain in a metastable state when the relative humidity drops below the deliquescence humidity (e.g. Tang, 1997; Pruppacher and Klett, 1997), aerosol chemistry is calculated in all model layers where the relative humidity had previously exceeded the deliquescence humidity but is still higher than the crystallisation humidity. Calculation of aqueous phase chemistry is however, terminated if the total water mass in one aerosol size class drops below a threshold value of $10^{-13} \mathrm{~m}_{(\mathrm{aq})}^{3} / \mathrm{m}_{(\text {air) }}^{3}$ which is necessary in order to keep the chemistry mechanism numerical stable (Kerkweg et al., 2007). To re-activate aerosol phase chemistry, the ambient relative humidity has to exceed the deliquescence humidity of the particles.

\section{Model setup}

\subsection{Lagrangian runs}

To investigate bromine chemistry over the Dead Sea and related ODEs a Lagrangian-kind model setup was chosen which can be understood as follows: the model column first moves over the desert for two days and then crosses the Dead Sea from South to North. The temperature ranges from about $42^{\circ} \mathrm{C}$ directly above the ground to about $22^{\circ} \mathrm{C}$ at the top of the boundary layer during day. During the nights temperature decreases below $20^{\circ} \mathrm{C}$ close to the surface. Relative humidity increases from $40 \%$ in the lowest metres above the ground to a value of about $80 \%$ at the top of the boundary layer at about $1500 \mathrm{~m}$ altitude during day. Chemistry is initialised such that average background mixing ratios for $\mathrm{O}_{3}$ 

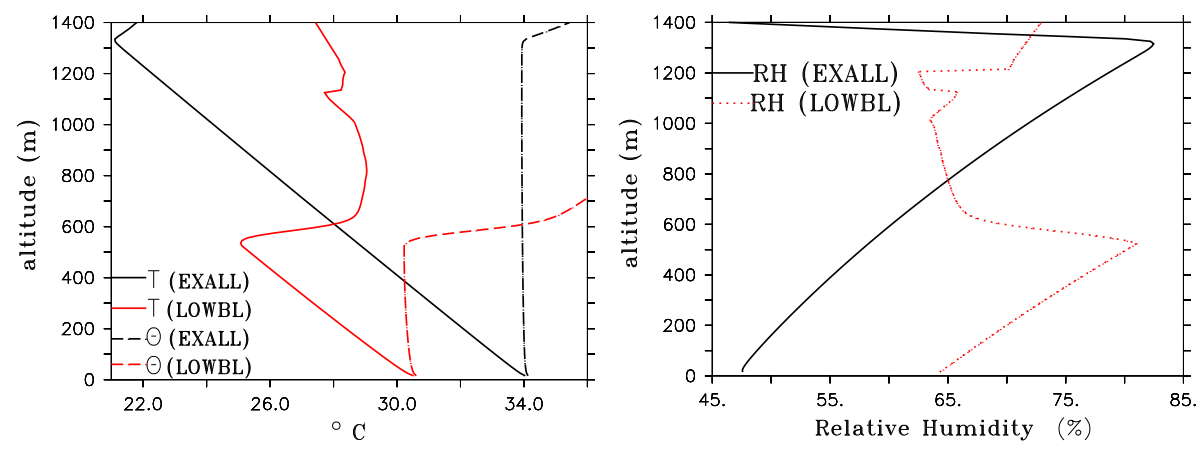

Fig. 2. The plot on the left shows the vertical gradient of the temperature $\left({ }^{\circ} \mathrm{C}\right.$, solid lines) and the potential temperature $\left({ }^{\circ} \mathrm{C}\right.$, dashed lines) at 11:30 for scenarios EXALL (black) and LOWBL (red). The plot on the right shows the vertical gradient of the relative humidity (in \%) at 11:30 for scenarios EXALL (black solid line) as well as scenario LOWBL (red dashed line).

Table 1. Overview of all scenarios.

\begin{tabular}{ll}
\hline NOEX & No air-sea exchange of gases is calculated \\
EX & Air-Sea exchange of only $\mathrm{BrCl}_{1} \mathrm{Br}_{2}, \mathrm{Cl}_{2}$ is calculated \\
EXALL & The same setup as EX, but air-sea exchange of $\mathrm{BrCl}_{1} \mathrm{Br}_{2}, \mathrm{Cl}_{2}, \mathrm{HOCl}, \mathrm{HOBr}, \mathrm{HCl}, \mathrm{HBr}$ is calculated \\
EXLIM & The same setup as EXALL, but limited vertical transport for first 90 min, strong vertical mixing for rest of simulation time \\
ENH & The same setup as EXALL, but strong hot spot emissions within the first $2 \mathrm{~h}$ \\
LOWBL & The same setup as EXALL, but boundary layer height only $500 \mathrm{~m}$ \\
STAT & The same initial conditions as EX, but model runs for $38 \mathrm{~h}$ over the same site at the South end of the Dead Sea \\
\hline
\end{tabular}

are about $70 \mathrm{nmol} / \mathrm{mol}$ and $1 \mathrm{nmol} / \mathrm{mol}$ for $\mathrm{NO}_{2}$ at the morning of day two in the initialisation model run. Figure 2 shows typical vertical profiles of temperature, potential temperature and relative humidity over the Dead Sea for two scenarios which will be introduced below. The temperature inversion indicates the boundary layer height in the model.

To initialise chemistry in the Dead Sea water, a separate model run was calculated for two days prohibiting air-sea exchange in order to have a spin up. It is assumed that the model column crosses the lake from South to North. By using this pseudo-Lagrangian approach, the influence of the gradient in chemical composition of the lake's water on gas phase concentrations can be taken into account. Furthermore, no unrealistic or speculative assumptions about advection into the model domain have to be made. The potential implications of such an idealised model setup will be addressed in the discussion of the model results in Sect. 8 . Based on the low wind speed reported by Hebestreit et al. (1999) and Matveev et al. (2001) we assume a horizontal wind speed of $3 \mathrm{~m} / \mathrm{s}$ for our model simulations such that it would take six hours to transport an air parcel across the Dead Sea. During those six hours when the model is run over the water surface, the lower boundary conditions are changed representing the measured gradient in the acidity and salinity of the lake water which are factors that are assumed to be responsible for the stronger and more often occurring $\mathrm{O}_{3}$ depletion events over the southern part of the Dead Sea. Based on values reported by Tas et al. (2005) $\mathrm{Br}^{-}$mixing ratios in the Dead Sea water are decreased from $0.15 \mathrm{~mol} / \mathrm{l}$ (South) to $0.05 \mathrm{~mol} / \mathrm{l}$ (North) and the $\mathrm{pH}$ of the lake is increased from 4.6 (South) to 6.4 (North). Obviously, this setup only changes the bromide content of the water and not the total salt content. Even the lowest reported $\mathrm{Cl}^{-}$concentrations for the Dead Sea water $(6.34 \mathrm{~mol} / \mathrm{l}$, Tas et al., 2005) are very large compared to ocean water and sensitivity studies showed that they do not limit the extent of halogen chemistry.

An overview of the different scenarios and the abbreviations of each model run is given in Table 1. In all scenarios the model column moves over the Dead Sea from 10:00 until 16:00 (all times refer to local time). The dry and hot meteorological conditions lead to a boundary layer height that is constantly at $\approx 1300 \mathrm{~m}$ if not mentioned otherwise.

We used the following Lagrangian model scenarios to simulate the effect of differing ambient conditions on the trace gas concentrations over the Dead Sea:

- NOEX: air-sea exchange of gases is not explicitly calculated and only the "standard" gas phase and aerosol phase chemistry of the model MISTRA is taken into account.

- EX: degassing of the halogen species $\mathrm{BrCl}, \mathrm{Br}_{2}$ and $\mathrm{Cl}_{2}$ out of the Dead Sea water into the atmosphere is calculated explicitly.

- EXALL: additionally to $\mathrm{BrCl}, \mathrm{Br}_{2}$ and $\mathrm{Cl}_{2}$, the air-sea exchange of $\mathrm{HOBr}, \mathrm{HOCl}, \mathrm{HCl}$ and $\mathrm{HBr}$ is considered 

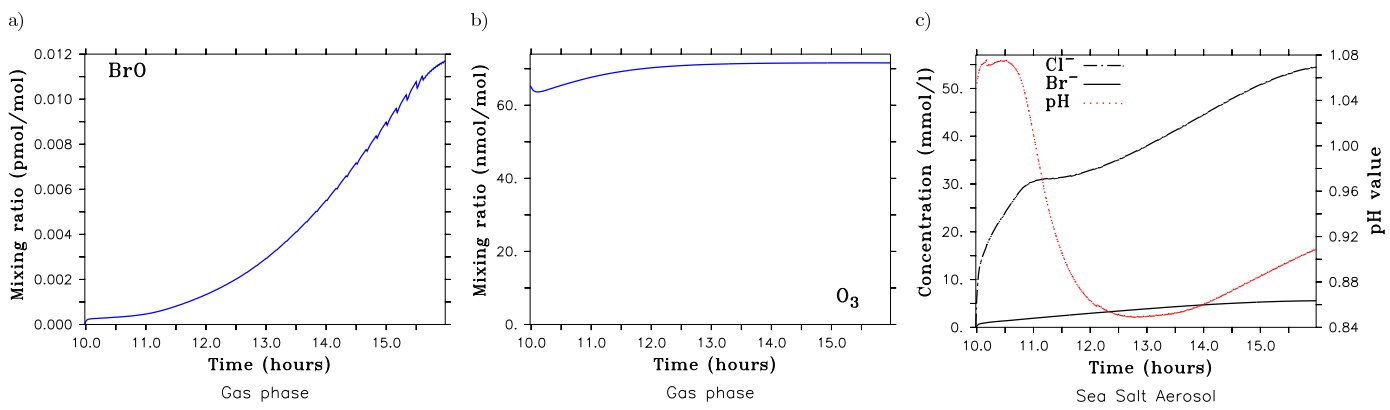

Fig. 3. Plots (a, b) show gas phase mixing ratios at $2 \mathrm{~m}$ altitude for scenario NOEX. Aqueous phase concentrations in sea salt aerosols at again $2 \mathrm{~m}$ height for scenario NOEX are shown in (c).

explicitly. In scenarios EXLIM, ENH and LOWBL the same tracers are exchanged like in EXALL.

- EXLIM: for the first two hours of simulation time vertical transport is strongly limited. Such a situation might arise when hot and dry air masses that had been transported over the desert start to cross the water surface which is slightly cooler than the land surface. An inversion which is not very intense but strong enough to limit vertical transport builds up in the lower most boundary layer. After about two hours it is broken up due to vertical mixing of air masses.

- ENH: fluxes of bromine species out of the Dead Sea water are increased in the first two hours of simulation time to simulate a potentially stronger bromine source. Salt pans which are mainly present in the southern part of the Dead Sea might be a strong additional bromine source. Furthermore, it is possible that the air-sea parameterisation underestimates the flux of bromine species out of the very shallow and highly concentrated evaporation ponds in the South.

- LOWBL: initial meteorological conditions were chosen such, that the boundary layer height is constantly at about $500 \mathrm{~m}$. To achieve this the temperature had to be decreased by about $3^{\circ} \mathrm{C}$ compared to scenario EXALL as can be seen in Fig. 2.

\subsection{Stationary run}

To investigate the daily variation of trace gas concentrations at one single point above the Dead Sea, one stationary model run (STAT) over the South end of the Dead Sea (Dead Sea water with a $\mathrm{pH}$ of 4.8 and $\left.\left[\mathrm{Br}^{-}\right]=0.15 \mathrm{~mol} / \mathrm{l}\right)$ was performed. The model run was initialised with the same fields for meteorology and chemistry as the Lagrangian studies, but the composition of the water as well as the composition of freshly emitted sea salt particles is not changed during the $38 \mathrm{~h}$ of simulation time. The model run starts at the same time as the Lagrangian runs (10:00) and all presented plots show mixing ratios between 10:00 day 1 and 20:00 day 2 .
It is rather unrealistic, that the air at one particular site at the Dead Sea stays uninfluenced by the environment. Thus advective fluxes are assumed however, only of $\mathrm{O}_{3}$ and $\mathrm{NO}_{2} . \quad$ As it is not possible to calculate advection into the model domain explicitly with a one-dimensional model, the strength of the fluxes is chosen somewhat arbitrarily (10:00 day 1-15:00 day $2: \mathrm{NO}_{2}: 0.463 \mathrm{pmol} /(\mathrm{mol} \mathrm{s})$, $\mathrm{O}_{3}: 0.078 \mathrm{pmol} /(\mathrm{mol} \mathrm{s}) ; 15: 00$ day $2-24: 00$ day $2: \mathrm{NO}_{2}$ : $0.347 \mathrm{pmol} /(\mathrm{mol} \mathrm{s}), \mathrm{O}_{3}: 6.829 \mathrm{pmol} /(\mathrm{mol} \mathrm{s})$. The inflow of both species into the model domain is assumed to be the same in all model levels. The assumption of an inflow in general is a strong constraint to the model. This scenario is not valid for representing accurately the conditions and daily variations at one particular site at the Dead Sea. As it is our objective to simulate the general (chemical) features observed at the Dead Sea this scenario is not meant to represent one specific measurement day. Anyhow, no meteorological data has been published for the measurement periods at the Dead Sea which could be used for comparison. However, scenario STAT should help to better understand the general chemical mechanism and its sensitivity to changing background conditions.

\section{Results: Lagrangian runs}

\subsection{Lagrangian runs without air-sea-exchange}

First we will discuss the scenario ignoring direct air-sea exchange (NOEX). If not mentioned otherwise all line plots presented herein show mixing ratios at two metres altitude as most measurements were taken at approximately this height. Only the time period when the model column moves over the Dead Sea (from 10:00 to 16:00) is shown in all plots.

The maximum $\mathrm{BrO}$ mixing ratio as simulated in scenario NOEX is $0.012 \mathrm{pmol} / \mathrm{mol}$ (Fig. 3a). This value which is reached at 16:00, is up to four orders of magnitude lower than values reported from measurements. $\mathrm{O}_{3}$ mixing ratios stay nearly constant at about $70 \mathrm{nmol} / \mathrm{mol}$ (Fig. 3b) during the six hours of simulation time between 10:00 (South) and 16:00 (North). 

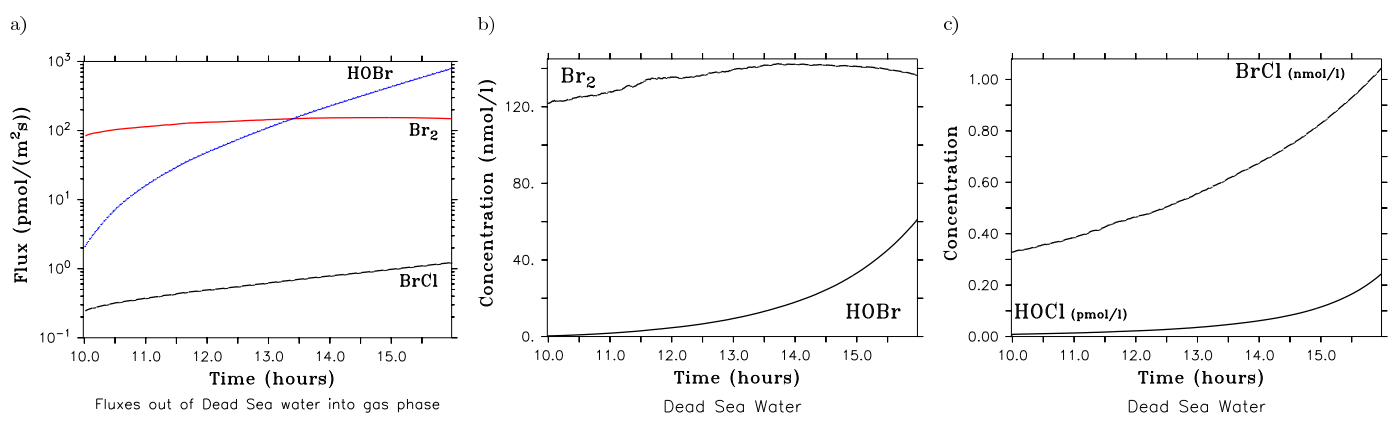

Fig. 4. The fluxes of $\mathrm{Br}_{2}$ (red solid line), $\mathrm{BrCl}$ (black dashed line) and $\mathrm{HOBr}$ (blue dotted line) out of the Dead Sea water are shown (a). Plots (b) and (c) show concentrations of several bromine containing species in the Dead Sea Water. All plots refer to scenario EXALL.

Without considering degassing out of the Dead Sea water the only source for gas phase bromine species is the transfer of halogen precursor species out of sea salt aerosols. Even though sea salt aerosols over the Dead Sea contain high $\mathrm{Br}^{-}$ and $\mathrm{Cl}^{-}$concentrations $(\approx 3$ and $40 \mathrm{mmol} / \mathrm{l} \mathrm{Fig.} 3 \mathrm{c}$ ) and have a high acidity ( $\mathrm{pH} \approx 1$, Fig. $3 \mathrm{c}$ ), it is not possible to reproduce the measurements with model setup NOEX. As the sea salt production is low and aerosol chemistry is only effective in the lowest $2 \mathrm{~m}$ a.s.l. due to the low relative humidity (see Fig. 2), the $\mathrm{Br}_{2}$ flux out of aerosol particles $\left(6 \times 10^{-7}\right.$ $\left.2.8 \times 10^{-6} \mathrm{pmol} /\left(\mathrm{m}^{3} \mathrm{~s}\right)\right)$ is too weak to produce significant bromine levels in the gas phase. Beside the vertical limitation of bromine production, strong vertical transport is another limiting factor for the accumulation of $\mathrm{BrO}$ in the lowest metres above ground as it leads to a quick vertical mixing of the anyway low concentrated tracers all over the boundary layer.

In general mixing ratios of gas phase halogen species increase with time (in terms of the Lagrangian model setup with travel distance), as at the south end of the Dead Sea (10:00) halogen concentrations are close to zero, and the longer halogen chemistry is active (the closer the model column gets to the north end of the lake) the more the concentrations increase. The relative increase (e.g. in $\mathrm{BrO}$ mixing ratios) is thus large, however, the absolute mixing ratios are very small.

Generally, the low relative humidity and thus the very low liquid water content of sea salt aerosols $\left(11 \times 10^{12} \mathrm{~m}_{\mathrm{aq}}^{3} / \mathrm{m}_{\mathrm{gas}}^{3}\right)$ is the reason for the slow recycling of bromine species on aerosol particles. The lower the liquid water content of an aerosol particle, the lower is the uptake rate of a gas phase species.

The production of $\mathrm{Br}_{2}$ in the aerosol phase by the bromine explosion reaction is essential for the formation of significant gas phase BrO levels. However, in addition to the high acidity and salinity in the aerosol, significant $\mathrm{HOBr}$ levels are required. As the halogen cycling between the gas- and aerosol phase is weak, $\mathrm{HOBr}$ uptake into aerosols is weak leading to the relatively small $\mathrm{HOBr}$ concentrations within sea salt particles $\left(\approx 5 \times 10^{-4} \mathrm{pmol} / \mathrm{l}\right)$. The recycling pathway via heterogeneous decomposition of $\mathrm{BrONO}_{2}$ is inefficient in our model simulations due to the limited uptake of gas phase species on aerosol particles due to the low relative humidity over the Dead Sea.

In a sensitivity test, the wind speed in scenario NOEX was increased such that it constantly exceeded $15 \mathrm{~m} / \mathrm{s}$. Even under these conditions $\mathrm{BrO}$ mixing ratios at $2 \mathrm{~m}$ altitude only increased up to $5 \mathrm{pmol} / \mathrm{mol}$ after six hours of simulation time. Clearly the model setup only including the interacting gas- and aerosol phase chemistry is not appropriate to simulate ozone depletion events and $\mathrm{BrO}$ levels in the range of $100 \mathrm{pmol} / \mathrm{mol}$. Therefore in the following air-sea exchange of halogen species is taken into account.

\subsection{Lagrangian runs with air-sea-exchange}

\subsubsection{Air-sea exchange and water chemistry}

First, the fluxes of bromine and chlorine species out of (into) the water of the Dead Sea and chemistry taking place in the Dead Sea water are discussed. Only fluxes for scenario EXALL are shown as the magnitude of fluxes as well as aqueous phase concentrations in the water do not differ significantly between the scenarios however, $\mathrm{HOBr}$ fluxes are not included in scenario EX. Figure 4a shows fluxes (in $\mathrm{pmol} /\left(\mathrm{m}^{2} \mathrm{~s}\right)$ ) for $\mathrm{Br}_{2}$ (red line), $\mathrm{BrCl}$ (black dashed line) and $\mathrm{HOBr}$ (blue dotted line) out of the Dead Sea water into the gas phase. Fluxes of all other halogen species are more than three orders of magnitude lower than the $\mathrm{BrCl}$ flux (which is the smallest flux shown) and are thus of minor importance and will not be discussed any further.

The strength of degassing of $\mathrm{Br}_{2}\left(80-154 \mathrm{pmol} /\left(\mathrm{m}^{2} \mathrm{~s}\right)\right)$ stays on the same order of magnitude during the simulation time. The change with time for both other fluxes plotted in the same figure is much larger. $\mathrm{BrCl}$ and $\mathrm{HOBr}$ fluxes increase from 0.23 to $1.22 \mathrm{pmol} /\left(\mathrm{m}^{2} \mathrm{~s}\right)$ and 2 to $800 \mathrm{pmol} /\left(\mathrm{m}^{2} \mathrm{~s}\right)$, respectively. As explained above, $\mathrm{Br}^{-}$and $\mathrm{H}^{+}$concentrations in the Dead Sea water are decreased during the six hours that the model column moves from the South to the North of the Dead Sea. Regarding those background conditions it is surprising that $\mathrm{Br}_{2}$ fluxes stay nearly constant and $\mathrm{HOBr}$ and $\mathrm{BrCl}$ fluxes even increase with time. 
Concentrations of $\mathrm{HOBr}$ in the water rise from $0.29 \mathrm{nmol} / \mathrm{l}$ to $61 \mathrm{nmol} / 1$ which is an increase of two orders of magnitude (Fig. 4b). Concentrations of $\mathrm{Br}_{2}$ in the water slightly increase in the first three hours of simulation time from about $121 \mathrm{nmol} / \mathrm{l}$ to $142 \mathrm{nmol} / \mathrm{l}$ and then decrease slightly to about $136 \mathrm{nmol} / \mathrm{l}$ (Fig. 4b). The most important reaction for activating bromine chemistry is the bromine explosion mechanism (red reaction path in Fig. 5):

$\mathrm{HOBr}+\mathrm{Br}^{-}+\mathrm{H}^{+} \rightleftharpoons \mathrm{Br}_{2}$

Even though bromide concentrations and the acidity in the water are decreased with time in the model, they remain high enough such that the equilibrium reactions produce $\mathrm{Br}_{2}$ throughout the simulation time (indicated through the larger red arrow in Fig. 5 pointing at $\mathrm{Br}_{2}$ ). The forward reaction (of Reaction R1) is getting only slightly slower in the last two hours between 14:00 and 16:00 as $\mathrm{Br}^{-}$and $\mathrm{H}^{+}$get less abundant with time, leading to the small decrease in $\mathrm{Br}_{2}$ concentrations followed by a decrease in the $\mathrm{Br}_{2}$ flux. Even though $\mathrm{Br}^{-}$concentrations decrease to about a third of their initial value after $6 \mathrm{~h}$ of simulation time $(0.15 \longrightarrow 0.05 \mathrm{~mol} / \mathrm{l})$, the absolute concentrations at 16:00 are still very large. Furthermore, $\mathrm{HOBr}$ concentrations increase strongly with time, which will be explained below. Thus the ratio of the forward to the backward reaction of the equilibrium Reaction (R1) even increases slightly with time, but the absolute reaction rate slightly decreases with time. This explains why the bromine explosion reaction does not get significantly slower with time and the decrease in $\mathrm{Br}_{2}$ concentrations in the Dead Sea water with time is negligibly small. Additionally the increase of the $\mathrm{pH}$ to a value of 6.4 (thus the water is still slightly acidic) at 16:00 does not yet limit $\mathrm{Br}_{2}$ formation significantly compared to a value of 5 (Fickert et al., 1999).

In contrast to $\mathrm{Br}_{2}, \mathrm{HOBr}$ concentrations increase nearly exponentially with time. Besides for the conversion of $\mathrm{Br}^{-}$ into $\mathrm{Br}_{2}, \mathrm{HOBr}$ is needed to convert $\mathrm{Cl}^{-}$into $\mathrm{BrCl}$ (green reaction path in Fig. 5):

$\mathrm{HOBr}+\mathrm{Cl}^{-}+\mathrm{H}^{+} \rightleftharpoons \mathrm{BrCl}$

Due to the very high $\mathrm{Cl}^{-}$and $\mathrm{H}^{+}$concentrations this reaction is very fast. Throughout the $6 \mathrm{~h}$ of simulation time the backward reaction of the equilibrium Reaction (R2) is faster (indicated by large green arrows in Fig. 5 pointing at $\mathrm{HOBr}$ and $\mathrm{Cl}^{-}$) than the forward reaction. Thus the backward reaction is a net source for HOBr in the Dead Sea water. In contrast, within aerosol particles, the forward reaction is in general faster than the backward reaction and $\mathrm{BrCl}$ is net produced. The explanation for the shift of the equilibria in the Dead Sea water can be found in the very high salt content and the very high and changing bromide content as well as the very low and changing $\mathrm{pH}$ of the Dead Sea water. Apart from Reaction $\mathrm{R} 2, \mathrm{BrCl}$ is produced by other $\mathrm{pH}$ dependent but non-equilibrium reactions within the water of which the

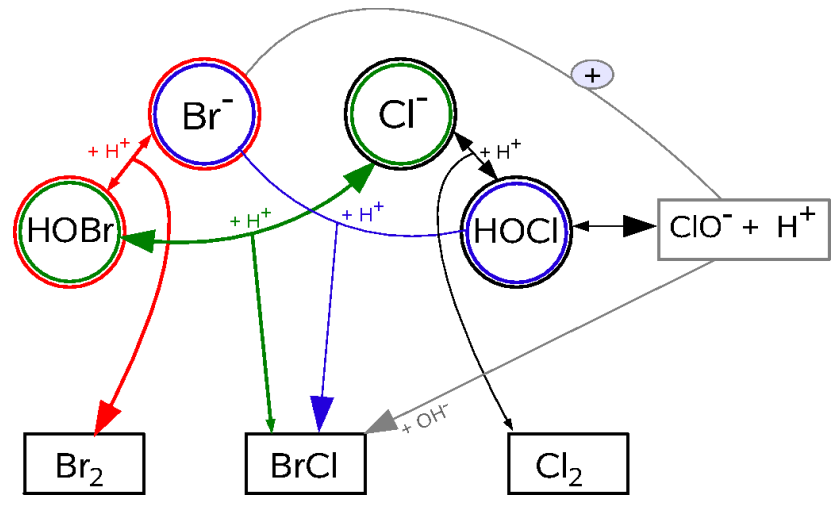

Fig. 5. Chemical aqueous phase equilibria. Large arrows indicate whether the forward or backward reaction tends to dominate.

fastest two are shown in Fig. 5 (blue and grey reaction path in Fig. 5):

$\mathrm{HOCl}+\mathrm{Br}^{-}+\mathrm{H}^{+} \longrightarrow \mathrm{BrCl}$

$\mathrm{Br}^{-}+\mathrm{ClO}^{-}+\mathrm{H}^{+} \longrightarrow \mathrm{BrCl}+\mathrm{OH}^{-}$.

Thus the slow production of $\mathrm{BrCl}$ via Reaction ( $\mathrm{R} 2$ ) is overcompensated by $\mathrm{BrCl}$ production via Reactions ( $\mathrm{R} 3$ and $\mathrm{R} 4$ ). The increase of $\mathrm{HOBr}$ as well as of $\mathrm{HOCl}$ concentrations in the Dead Sea water from South to North can be seen as follows: As both $\mathrm{H}^{+}$and $\mathrm{Br}^{-}$concentrations decrease with time, less $\mathrm{HOCl}$ is consumed with time forming $\mathrm{BrCl}$ (via Reaction (R3), blue reaction path in Fig. 5). This leads to an increase of $\mathrm{HOCl}$ concentrations followed by a stronger net production of $\mathrm{ClO}^{-}$via the equilibrium reaction:

$\mathrm{HOCl} \rightleftharpoons \mathrm{ClO}^{-}+\mathrm{H}^{+}$

(black reaction path in Fig. 5) followed by a stronger production of $\mathrm{BrCl}$ (via Reaction (R4), grey reaction path in Fig. 5). This now leads to an increase in $\mathrm{BrCl}$ concentrations followed by a stronger conversion to $\mathrm{HOBr}$ (via $\mathrm{Re}$ action (R2), green reaction path in Fig. 5). The strongly increasing $\mathrm{HOBr}$ concentrations in the water determine the strength of the $\mathrm{HOBr}$ flux into the atmosphere which exceeds the $\mathrm{Br}_{2}$ flux (after 13:40) even though hypobromous acid is more soluble than $\mathrm{Br}_{2}$.

\subsubsection{Gas phase chemistry}

For both scenario EXALL and EX, BrO mixing ratios increase rapidly within a few minutes after the model column is assumed to cross the Dead Sea up to $10 \mathrm{pmol} / \mathrm{mol}$ and increase further up to $151 \mathrm{pmol} / \mathrm{mol}$ (EXALL) and $102 \mathrm{pmol} / \mathrm{mol}$ (EX, Fig. 6a) indicating that the Dead Sea water itself has to be considered as an important source for gas phase bromine species as the calculation of air-sea exchange is necessary in the model to simulate $\mathrm{BrO}$ mixing ratios on the same order of magnitude 

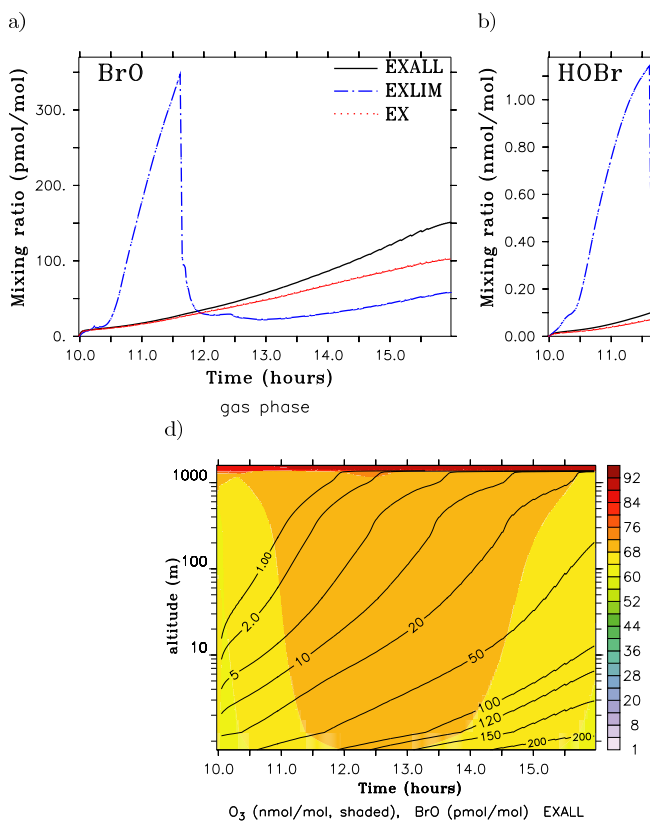

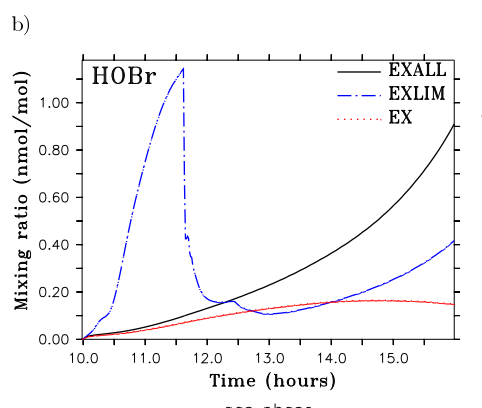

c)

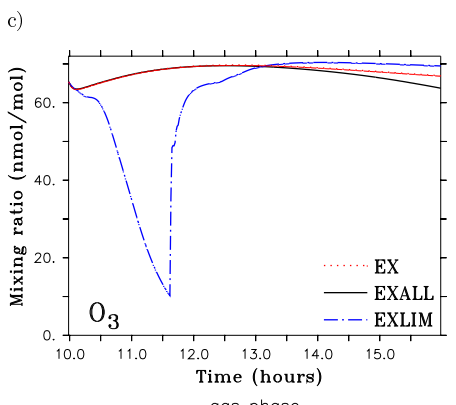

gas phase

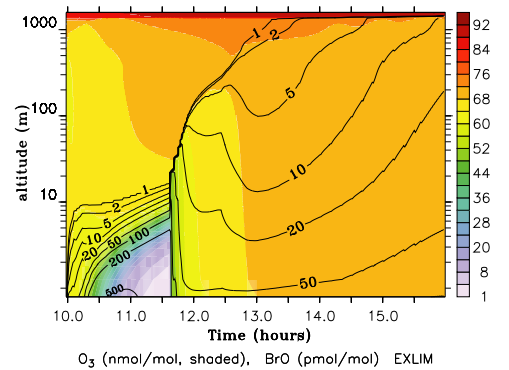

Fig. 6. Plotted are gas phase mixing ratios at $2 \mathrm{~m}$ altitude for scenarios EX (red dotted line), EXALL (black line) and EXLIM (blue dashdotted line) for the six hours that the model crosses the Dead Sea. The vertical distribution of $\mathrm{O}_{3}$ (shaded) and $\mathrm{BrO}$ (contour lines) is shown in addition for scenarios EXALL (d) and EXLIM (e). Note the logarithmic scaling of the y-axis.

as field measurements show. The difference of about $50 \mathrm{pmol} / \mathrm{mol} \mathrm{BrO}$ between scenario EX and EXALL can be explained with the very high gas phase $\mathrm{HOBr}$ mixing ratios in scenario EXALL $\left([\mathrm{HOBr}]_{\max }=0.91 \mathrm{nmol} / \mathrm{mol}\right.$, EX: $[\mathrm{HOBr}]_{\max }=0.14 \mathrm{nmol} / \mathrm{mol}$ ) caused by the additional $\mathrm{HOBr}$ source due to direct degassing out of the Dead Sea water (Fig. 6b). $\mathrm{HOBr}$ is under the prevailing circumstances an important precursor species for gas phase bromine as it is rapidly photolysed to form $\mathrm{Br}$ atoms (and $\mathrm{OH}$ radicals) which react with $\mathrm{O}_{3}$ to produce $\mathrm{BrO}$. Under less dry atmospheric conditions, $\mathrm{HOBr}$ is taken up into sea salt aerosols quickly due to its high solubility. However, as the liquid water content of aerosol particles is very low, the uptake of gas phase species in aerosol particles is not efficient. As the source of $\mathrm{HOBr}$ due to degassing out of the Dead Sea water is large, a significant fraction of $\mathrm{HOBr}$ gets photolysed and provides an efficient source for $\mathrm{Br}$ atoms.

The steadily and strongly increasing $\mathrm{BrO}$ mixing ratios in scenario EXALL and EX are caused by the constantly strong fluxes of bromine species out of the water. The most important source reaction of bromine atoms is photolysis of molecular bromine. Even though gas phase $\mathrm{Br}_{2}$ gets quickly photolysed to Br (by Reaction R6):

$\mathrm{Br}_{2}+\mathrm{h} \nu \longrightarrow 2 \mathrm{Br}$

$\mathrm{Br}+\mathrm{O}_{3} \longrightarrow \mathrm{BrO}+\mathrm{O}_{2}$

the reaction rate is in the range of $10-40 \mathrm{pmol} /\left(\mathrm{m}^{3} \mathrm{~s}\right)$ at $2 \mathrm{~m}$ altitude (EXALL). Regarding all $\mathrm{Br}_{2}$ source and sink reactions, the large additional source of bromine compounds due to the air-sea exchange $\left(81-154 \mathrm{pmol} /\left(\mathrm{m}^{2} \mathrm{~s}\right)\right)$ leads to an accumulation of bromine in the air. Even though the largest source and sink reactions for $\mathrm{Br}_{2}$ are on the same order of magnitude, the source of gas phase $\mathrm{Br}_{2}$ due to air-sea exchange is slightly larger than the $\mathrm{Br}_{2}$ photolysis throughout the simulation time.

$\mathrm{BrO}$ mixing ratios in scenario EXALL tend to increase with time throughout the boundary layer. From 13:00 on mixing ratios exceed $5 \mathrm{pmol} / \mathrm{mol}$ even at $1000 \mathrm{~m}$ altitude (Fig. 6d) and increase further at this height up to $20 \mathrm{pmol} / \mathrm{mol}$ at 16:00, when the model column reaches the North shore of the Dead Sea. There is a delay of about one hour between the start of the model run at 10:00 when BrO surface values exceed $1 \mathrm{pmol} / \mathrm{mol}$ after a few minutes until $\mathrm{BrO}$ mixing ratios in $1000 \mathrm{~m}$ also exceed $1 \mathrm{pmol} / \mathrm{mol}$ at 11:00.

Even though $\mathrm{BrO}$ gets quickly distributed all over the boundary layer, the strong vertical gradient in mixing ratios is striking (note the logarithmic scaling of the contour lines in plots showing $\mathrm{BrO}$ mixing ratios in Fig. 6d, e). $\mathrm{BrO}$ mixing ratios at e.g. 15:30 are less than half the ground level values at $10 \mathrm{~m}$ altitude $(240 \mathrm{pmol} / \mathrm{mol} \longrightarrow 90 \mathrm{pmol} / \mathrm{mol})$ and at $100 \mathrm{~m}$ altitude they are almost a factor of four smaller than mixing ratios directly above the Dead Sea water surface.

The influence of those high bromine concentrations, as simulated in scenario EXALL (and EX), on $\mathrm{O}_{3}$ chemistry are still small though. The decrease from 69 to $63 \mathrm{nmol} / \mathrm{mol}$ (EXALL) is insignificant compared to the observed depletion events. The difference in $\mathrm{O}_{3}$ mixing ratios in scenario EXALL means an $\mathrm{O}_{3}$ reduction of only $9 \%$. 
In Scenario EXLIM vertical transport is limited in the first two hours of simulation time leading to the sharp increase in $\mathrm{BrO}$ mixing ratios between 10:00 and 11:40 from below 1 up to $395 \mathrm{pmol} / \mathrm{mol}$ and the likewise quick decrease to about $30 \mathrm{pmol} / \mathrm{mol}$ between 11:40 and 13:00 when the inversion is broken up (Fig. 6b, blue dash-dotted line). Simultaneous to the very fast increase of $\mathrm{BrO}$ mixing ratios in the first $1.5 \mathrm{~h}$ that the model crosses the Dead Sea, $\mathrm{O}_{3}$ mixing ratios decrease until they reach a minimum of $9.3 \mathrm{nmol} / \mathrm{mol}$ at 11:40 (Fig. 6c, blue dash-dotted line). However, as soon as the low - level inversion is compensated, $\mathrm{O}_{3}$ quickly reaches background mixing ratios of about $69 \mathrm{nmol} / \mathrm{mol}$ due to vertical downmixing of $\mathrm{O}_{3}$.

The limited $\mathrm{O}_{3}$ destruction in scenario EXALL might be surprising at a first glance regarding the extraordinarily high $\mathrm{BrO}$ levels. Even though the net $\mathrm{O}_{3}$ destruction is larger than the net $\mathrm{O}_{3}$ production close to the Dead Sea water surface, the contribution of the strong $\mathrm{O}_{3}$ sink due to reaction with halogens to the total $\mathrm{O}_{3}$ mass balance is still not large enough to lead to a distinctive ODE.

As mixing ratios of bromine species show a strong vertical gradient, bromine mixing ratios in the upper boundary layer are not large enough anymore to destroy significant $\mathrm{O}_{3}$ levels. Thus vertical downmixing of $\mathrm{O}_{3}$ rich air from the upper boundary layer compensates the net $\mathrm{O}_{3}$ destruction in the lower most metres of the boundary layer. However, bromine mixing ratios permanently increase with time all over the boundary layer such that $\mathrm{O}_{3}$ destruction cannot be totally compensated anymore by vertical mixing leading to the slight decrease in $\mathrm{O}_{3}$ mixing ratios between 13:00 and 16:00.

As was discussed above $\mathrm{O}_{3}$ is depleted strongly and quickly in scenario EXLIM between 10:30 and 11:30. As bromine mixing ratios are high only in the lowest metres above sea level due to the limited vertical transport (Fig. 6e), $\mathrm{O}_{3}$ destruction is also restricted to the lowest $10-20 \mathrm{~m}$ of the boundary layer. Above this inversion layer $\mathrm{O}_{3}$ mixing ratios are again hardly affected by bromine chemistry. As soon as the inversion is broken up, $\mathrm{O}_{3}$ gets again rapidly well mixed throughout the whole boundary layer. After 13:30, when the boundary layer height quickly rises to $1300 \mathrm{~m}, \mathrm{BrO}$ is also quickly distributed all over the boundary layer and mixing ratios are between $2 \mathrm{pmol} / \mathrm{mol}$ and $50 \mathrm{pmol} / \mathrm{mol}$ all over the boundary layer (Fig. 6e).

\subsection{Enhanced fluxes}

With all of the Lagrangian scenarios presented above neither an ozone depletion event affecting the whole boundary layer could be simulated nor any significant $\mathrm{O}_{3}$ depletion in case of a deep and well mixed boundary layer. For scenario ENH the fluxes of halogen species out of the Dead Sea water were enhanced for the first two hours of simulation time which is the time the model is roughly assumed to cross the evaporation ponds.
Fluxes were enhanced by a factor of 30 until 10:30, a factor of 20 until 11:00 and a factor of 10 until 12:00. Afterwards, the fluxes as calculated by the air-sea exchange parameterisation are not modified anymore. BrO mixing ratios peak at 10:30, 11:00 and 12:00 as a response to the strong and instantaneous changes in the flux strength of $\mathrm{BrO}$ precursor species. Between 10:00 and 11:00 $\mathrm{BrO}$ mixing ratios reach values between 600 and $750 \mathrm{pmol} / \mathrm{mol}$ (red dotted line, Fig. 7c). Simultaneously $\mathrm{O}_{3}$ mixing ratios decrease from 65 to $47 \mathrm{nmol} / \mathrm{mol}$ (black line, Fig. 7c). As the strength of degassing is again decreased after 11:00, $\mathrm{BrO}$ mixing ratios decrease quickly to about $300 \mathrm{pmol} / \mathrm{mol}$ and drop further to about $100 \mathrm{pmol} / \mathrm{mol}$ after $12: 00$ and stay more or less constant around this value until 16:00. During the same time span $\mathrm{O}_{3}$ mixing ratios decrease constantly, but not very fast and reach a minimum value of $13 \mathrm{nmol} / \mathrm{mol}$ at 16:00.

The slow depletion of $\mathrm{O}_{3}$ affects the whole boundary layer up to an altitude of $1200 \mathrm{~m}$ (Fig. 7a). BrO mixing ratios are approximately $100 \mathrm{pmol} / \mathrm{mol}$ all over the boundary layer after 12:00 in scenario ENH whereas mixing ratios never exceeded $50 \mathrm{pmol} / \mathrm{mol}$ in altitudes greater than $100 \mathrm{~m}$ in scenario EXALL. Due to the enhanced fluxes during the first two hours of simulation time the bromine load all over the boundary layer is significantly higher in scenario ENH than in scenario EXALL during the whole simulation time. As a consequence $\mathrm{O}_{3}$ is destroyed all over the boundary layer by reaction with bromine in scenario $\mathrm{ENH}$, such that vertical mixing cannot compensate the depletion of $\mathrm{O}_{3}$ anymore as it happened in scenario EXALL. However, the reaction between bromine and $\mathrm{O}_{3}$ is not fast enough to lead to an immediate ODE such that a delay between the time of maximum $\mathrm{BrO}$ and minimum $\mathrm{O}_{3}$ mixing ratios can be seen (Fig. 7 a,c).

For scenario LOWBL different meteorological background conditions were assumed leading to a constantly much lower boundary layer $(500 \mathrm{~m})$ than in all other so far presented Lagrangian studies. Note that therefore the temperature in the atmosphere had to be decreased by more than $3^{\circ} \mathrm{C}$ (see Fig. 2) compared to the other scenarios and thus the relative humidity in scenario LOWBL is higher than in other scenarios all over the boundary layer (see Fig. 2). This also indicates that aerosol phase chemistry gains in importance as it is not only calculated in the lowest $2-4 \mathrm{~m}$ but also constantly in altitudes exceeding $300 \mathrm{~m}$. BrO gas phase mixing ratios increase with time as it was seen before (see Fig. 7b, d). Compared to scenario EXALL, they increase stronger with time $\left([\mathrm{BrO}]_{\max }=207 \mathrm{pmol} / \mathrm{mol}(\mathrm{LOWBL})\right.$ versus $[\mathrm{BrO}]_{\max }=151 \mathrm{pmol} / \mathrm{mol}(\mathrm{EXALL})$ ). Simultaneously to the increase in $\mathrm{BrO}$ mixing ratios, $\mathrm{O}_{3}$ mixing ratios decrease from 65 to $25 \mathrm{nmol} / \mathrm{mol}$ at $2 \mathrm{~m}$ altitude. As in scenario ENH the depletion of $\mathrm{O}_{3}$ affects the whole boundary layer (Fig. 7b). 
a)

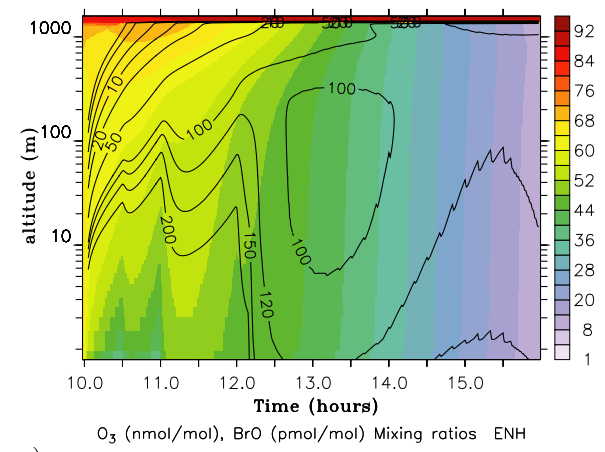

c)

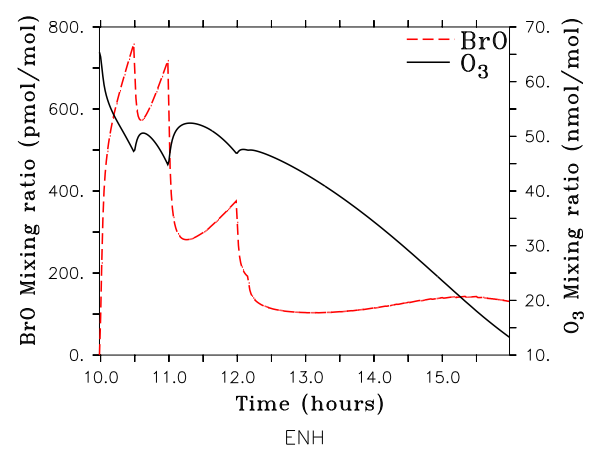

b)

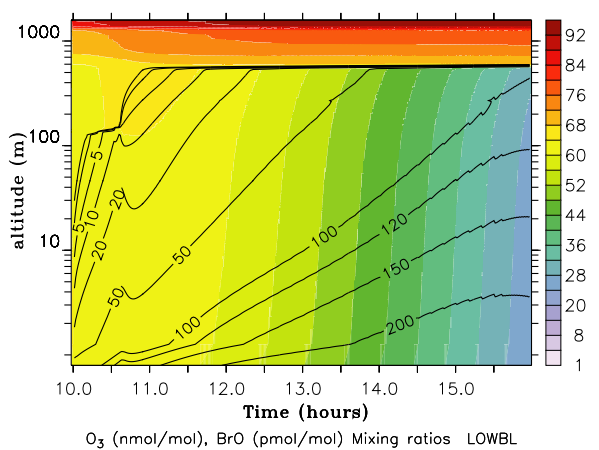

d)

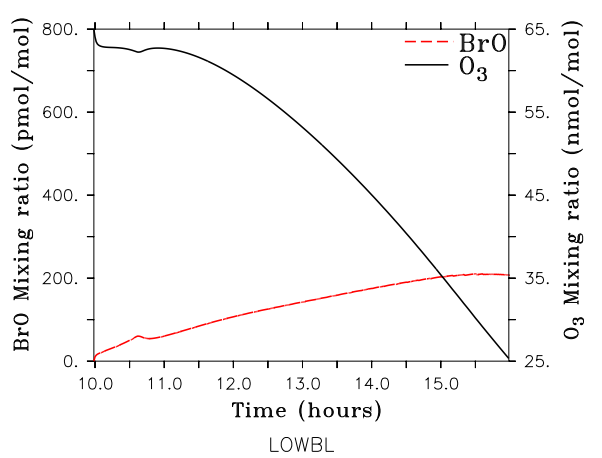

Fig. 7. Figures in the top row show $\mathrm{BrO}$ (contour lines, in pmol/mol) and $\mathrm{O}_{3}$ (shaded in $\mathrm{nmol} / \mathrm{mol}$ ) mixing ratios over the whole boundary layer for scenarios ENH (a) and LOWBL (b) for the six hours that the model crosses the Dead Sea. Note the logarithmic scaling of the y-axis. Figures in the bottom row show $\mathrm{BrO}$ (red dashed lines, in pmol/mol) and $\mathrm{O}_{3}$ (black solid lines, in $\mathrm{nmol} / \mathrm{mol}$ ) mixing ratios at $2 \mathrm{~m}$ altitude for scenarios ENH (c) and LOWBL (d).

\section{Stationary runs}

To study the influence of changing meteorological background conditions on tracer mixing ratios, scenario STAT was calculated. In comparison to scenario EX, maximum $\mathrm{BrO}$ mixing ratios on day 1 in scenario STAT are slightly lower: $[\mathrm{BrO}]_{\mathrm{EX}}$ : $100 \mathrm{pmol} / \mathrm{mol},[\mathrm{BrO}]_{\mathrm{STAT}}: 60 \mathrm{pmol} / \mathrm{mol}$ (Fig. 8a). $\mathrm{NO}_{2}$ mixing ratios are higher during the whole day in scenario STAT compared to scenario EX due to the prescribed advection of $\mathrm{NO}_{2}$ into the model domain (day 1 : $\left.\left[\mathrm{NO}_{2}\right]_{\mathrm{STAT}} \approx 0.8 \mathrm{nmol} / \mathrm{mol},\left[\mathrm{NO}_{2}\right]_{\mathrm{EX}} \approx 0.3 \mathrm{nmol} / \mathrm{mol}\right)$. Thus comparatively more $\mathrm{BrO}$ is consumed via the reaction

$\mathrm{BrO}+\mathrm{NO}_{2} \longrightarrow \mathrm{BrONO}_{2}$

leading mainly to the difference in $\mathrm{BrO}$ mixing ratios at day 1 between scenarios STAT and EX. On the second day of simulation time, BrO mixing ratios in scenario STAT increase stronger than on day 1 and reach a maximum value of $140 \mathrm{pmol} / \mathrm{mol}$ at $2 \mathrm{~m}$ altitude at about 10:00 in the morning. Mixing ratios decrease again after 10:00 $(34 \mathrm{~h}$ in Fig. $8=10: 00$ day 2) but are always larger than on day 1 . $\mathrm{BrO}$ mixing ratios exceed $50 \mathrm{pmol} / \mathrm{mol}$ up to an altitude of about $1200 \mathrm{~m}$ almost all day long whereas on day 1 they were al- ways lower than $12 \mathrm{pmol} / \mathrm{mol}$ in heights larger than $100 \mathrm{~m}$ (Fig. 8b, e).

Maximum $\mathrm{HOBr}$ mixing ratios at $2 \mathrm{~m}$ altitude on day 1 of the simulation time are of similar order of magnitude in scenarios STAT and EX. However, on the second day of simulation time, $\mathrm{HOBr}$ mixing ratios also increase to larger values than on day $1\left([\mathrm{HOBr}]_{\mathrm{EX}} \approx 165 \mathrm{pmol} / \mathrm{mol}\right.$ $[\mathrm{HOBr}]_{\text {STAT, day } 1} \approx 174 \mathrm{pmol} / \mathrm{mol}$, $[\mathrm{HOBr}]_{\text {STAT, day } 2} \approx 523 \mathrm{pmol} / \mathrm{mol}$, Fig. $8 \mathrm{a}, \mathrm{b}$ ).

Comparing the results from scenarios STAT and EX, the vertical distribution and the time evolution of $\mathrm{O}_{3}$ mixing ratios is surprising. On the first day of simulation time, $\mathrm{O}_{3}$ mixing ratios stay constant at around $70 \mathrm{nmol} / \mathrm{mol}$ and are not affected by halogen chemistry. On the second day $(30 \mathrm{~h}$ in Fig. 8=06:00 day 2) $\mathrm{O}_{3}$ mixing ratios start to decrease immediately after sunrise, when photochemistry and thus bromine chemistry starts getting activated. At 14:00, $\mathrm{O}_{3}$ mixing ratios at $2 \mathrm{~m}$ altitude reach a minimum value of $5 \mathrm{nmol} / \mathrm{mol}$ and increase again afterwards mainly because of the prescribed $\mathrm{O}_{3}$ flux and because mixing ratios of bromine species decrease in the late afternoon hours. In contrast to the Lagrangian scenarios discussed above, $\mathrm{O}_{3}$ is strongly depleted up to an altitude of about $1200 \mathrm{~m}$ even though the boundary layer is high and well mixed throughout the simulation time. Even 

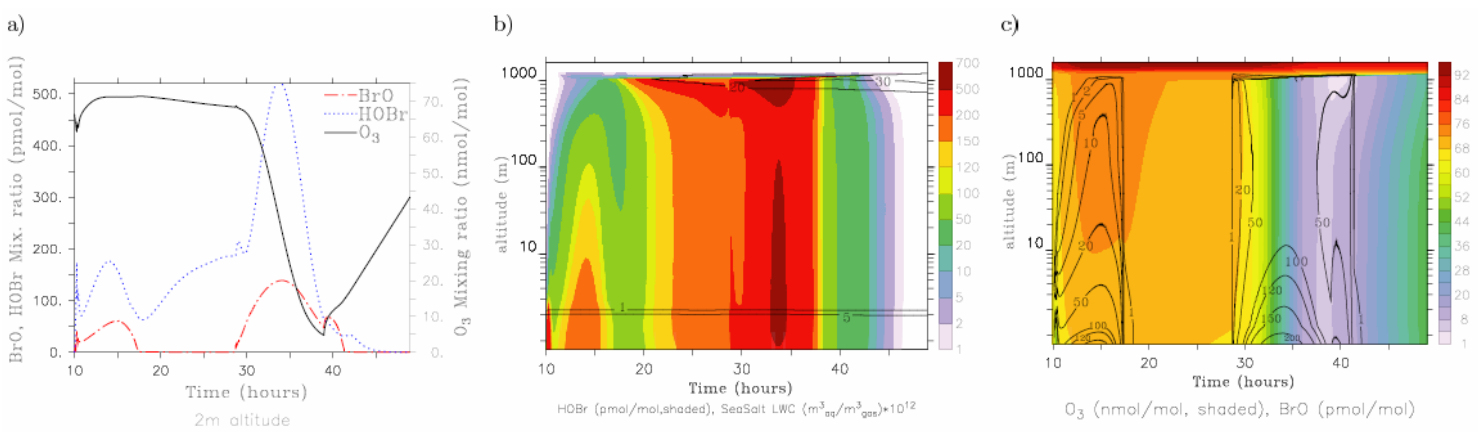

Fig. 8. All plots in this figure refer to scenario STAT. Plot (a) shows the time evolution at $2 \mathrm{~m}$ altitude of gas phase mixing ratios of $\mathrm{HOBr}$ (blue dotted line, pmol/mol), $\mathrm{BrO}$ (red dash-dotted line, pmol/mol) and $\mathrm{O}_{3}$ (black solid line, nmol/mol). Plot (b) shows the vertical distribution of $\mathrm{HOBr}$ mixing ratios (shaded, $\mathrm{pmol} / \mathrm{mol}$ ) and the liquid water content of sea salt aerosols (contour lines). Plot (c) shows the vertical distribution of $\mathrm{O}_{3}$ (shaded, $\mathrm{nmol} / \mathrm{mol}$ ) and $\mathrm{BrO}$ mixing ratios (contour, $\mathrm{pmol} / \mathrm{mol}$ ).

though $\mathrm{BrO}$ mixing ratios are on the same order of magnitude as e.g. in scenario EXALL where no influence on $\mathrm{O}_{3}$ chemistry could be found, the bromine oxide production in scenario STAT is sufficiently large to lead to a significant $\mathrm{O}_{3}$ depletion event.

Two factors contribute to the formation of the ODE: the (rather unrealistic) assumption that air masses are stagnant results in higher mixing ratio of halogens in the morning of the second day of the simulation compared to the first day. $\mathrm{Br}_{2}$ mixing ratios before sunrise on day 2 are $470 \mathrm{pmol} / \mathrm{mol}$ whereas they increase from 0 at 10:00 on day 1 when the model simulations start $\left(\left[\mathrm{Br}_{2}\right]_{\mathrm{STAT}}: 100 \mathrm{pmol} / \mathrm{mol}\right.$ at $10: 00$ day 2).

Furthermore, the strong $\mathrm{O}_{3}$ depletion is related to slightly changing meteorological background conditions from day 1 to day 2 . The temperature is lower and the relative humidity is higher on day 2 compared to day 1 . As explained in the model description the ambient relative humidity has to exceed the aerosol's deliquescence humidity of $75 \%$ (70\% for sulphate aerosols) to reactivate the calculation of sea salt (and respectively sulphate) aerosol chemistry in the model. On day 1 of the simulation time the relative humidity is below this threshold value all over the boundary layer but on day 2 it exceeds $75 \%$ at altitudes above $800 \mathrm{~m}$ (and $70 \%$ at altitudes above $650 \mathrm{~m}$ ) and thus aerosol phase (sulphate and sea salt) chemistry is reactivated (Fig. 8b). As a result, aqueous phase chemistry and the cycling of halogens on aerosol particles gains in importance. Within all levels having a LWC $>10^{12} \mathrm{~m}_{\mathrm{aq}}^{3} / \mathrm{m}_{\text {gas }}^{3}$ in Fig. 8b, liquid phase chemistry is activated in the model simulation (note again the logarithmic scaling of the y-axis in all plots showing vertical distributions!). A generally efficient recycling process is the heterogeneous decomposition of $\mathrm{BrONO}_{2}$ on sulphate aerosols and the subsequent release of $\mathrm{HOBr}$ out of aerosol particles:

$\mathrm{BrONO}_{2} \longrightarrow \mathrm{HOBr}_{\mathrm{aq}}+\mathrm{HNO}_{\mathrm{aq}}$

$\mathrm{HOBr}_{\mathrm{aq}} \longrightarrow \mathrm{HOBr}_{\mathrm{g}}$
Through strong vertical transport, also the lower part of the boundary layer is indirectly influenced by the enhanced halogen chemistry in the upper parts of the boundary layer. This can be seen in the vertical distribution of gas phase $\mathrm{HOBr}$ mixing ratios (Fig. 8b). As the total halogen recycling capacity all over the boundary layer is enhanced, $\mathrm{O}_{3}$ is depleted even though $\mathrm{BrO}$ mixing ratios do not exceed $200 \mathrm{pmol} / \mathrm{mol}$.

Even though the cycling of halogen species between the aerosol phase and the gas phase contributes to the increase in the gas phase halogen mixing ratios, the air-sea exchange of $\mathrm{Br}_{2}$ and $\mathrm{BrCl}$ is still the dominant source for $\mathrm{BrO}$ especially in the lowest part of the boundary layer. $\mathrm{BrO}$ mixing ratios still show a strong vertical gradient. The inflow of $\mathrm{O}_{3}$ into the model domain was increased in the afternoon hours of day 2 of simulation time, as otherwise $\mathrm{O}_{3}$ mixing ratios would not increase anymore. Almost all measurements show a quick increase of $\mathrm{O}_{3}$ mixing ratios in the late afternoon/early evening hours. However, a flux of $6.8 \mathrm{pmol} /(\mathrm{mol} \mathrm{s})$ of $\mathrm{O}_{3}$ was necessary to reach mixing ratios of at least $40 \mathrm{nmol} / \mathrm{mol}$ at $20: 00$ day 2 in the model.

One of the main conclusions which can be drawn from this idealised scenario is that it is important not only to consider chemistry as an isolated system as apparently in addition to changes in tracer concentrations, small changes in the meteorological background conditions (namely temperature and humidity) give a large feedback to chemistry.

\section{Discussion}

Considering the measurements taken at the Dead Sea in more detail, it can be seen that $\mathrm{BrO}$ mixing ratios in the North reach very regular maximum mixing ratios at noon and the standard variation of the measurements is very small. In the South however, the time of maximum $\mathrm{BrO}$ mixing ratios varies strongly as well as the absolute values of maximum BrO mixing ratios (Fig. 2 in Tas et al., 2003). In addition $\mathrm{O}_{3}$ seems to be destroyed more rapidly and more often over 
Table 2. Summary of results of scenarios calculated for the Dead Sea. All values refer to mixing ratios at $2 \mathrm{~m}$ altitude.

\begin{tabular}{lllrl}
\hline Scenario & $\mathrm{BrO}_{(\max )}[\mathrm{pmol} / \mathrm{mol}]$ & $\mathrm{O}_{3(\min )}[\mathrm{nmol} / \mathrm{mol}]$ & $\Delta \mathrm{O}_{3}$ & \\
\hline NOEX & 0.012 & const 69 & $0 \%$ & No air-sea-exchange, $\mathrm{BrO}<1$ pmol/mol, $\mathrm{O}_{3}$ not affected \\
EX & 102 & 66 & $4 \%$ & High BrO, No ODE \\
EXALL & 151 & 63 & $9 \%$ & High BrO, No ODE \\
EXLIM & 347 & 10 & $84 \%$ & ODE affects only lowest $20 \mathrm{~m}$ \\
ENH & 375 & 13 & $80 \%$ & ODE affects whole BL, $\mathrm{O}_{3}$ decrease still slow but steady \\
LOWBL & 207 & 25 & $63 \%$ & ODE affects whole BL, less strong than when enhancing fluxes \\
STAT & day 1: 61 & day 1: 70 & $0 \%$ & No ODE on day 1 but ODE on day 2 affecting the whole BL due to \\
& day 2: 139 & day 2: 5 & $92 \%$ & slightly differing meteorological background conditions \\
\hline
\end{tabular}

the Southern end of the Dead Sea than the Northern end (Tas et al., 2005; Zingler and Platt, 2005). With the Lagrangian scenario EXLIM it was possible to reproduce these measurements showing high $\mathrm{BrO}$ mixing ratios $(>60 \mathrm{pmol} / \mathrm{mol})$ all over the Dead Sea but an ODE only in the South. Results agree well regarding the strength of the ODE, the spatial distribution of $\mathrm{O}_{3}$ and $\mathrm{BrO}$ as well as the temporal evolution of the depletion event meaning a very quick $\mathrm{O}_{3}$ decrease when air masses are assumed to reach the Dead Sea from the South (see Fig. 6).

Nevertheless, the presence of $\mathrm{BrO}$ mixing ratios of almost $400 \mathrm{pmol} / \mathrm{mol}$ at $2 \mathrm{~m}$ altitude are necessary to destroy a significant amount of $\mathrm{O}_{3}$ in the model. However, it is possible that the effect of a low level inversion is overestimated in the model. It is likely that he inversion height in the model simulation is slightly too low. Furthermore, the inversion could be compensated faster in reality. Consequently it is likely that $\mathrm{BrO}$ mixing ratios would not become as high as in scenario EXLIM. To asses the potential overestimation of the inversion, scenario EXLIM was recalculated only allowing the exchange of $\mathrm{Br}_{2}$ and $\mathrm{BrCl}$ (not shown). In that case $\mathrm{BrO}$ mixing ratios reached a maximum mixing ratio of $290 \mathrm{pmol} / \mathrm{mol}$ (in contrast to $395 \mathrm{pmol} / \mathrm{mol}$ in EXLIM) and $\mathrm{O}_{3}$ still decreased quickly to $13 \mathrm{nmol} / \mathrm{mol}$ (in contrast to $10 \mathrm{nmol} / \mathrm{mol}$ in EXLIM). It is not possible to evaluate those model results, as the measurements were only taken at one level at approximately $2 \mathrm{~m}$ height and no information about the vertical extent of the real depletion events or BrO mixing ratios is available. For future studies it would be desirable to measure the vertical extent of the layer affected by ozone loss and possibly vertical profiles of BrO. Information about the vertical structure of the boundary layer (temperature, humidity) would also be very helpful.

\subsection{Idealised pseudo-lagrangian model setup}

The assumption for the lagrangian scenarios that the wind direction is southerly all over the lake might be idealised. Regarding the wind direction data given by Matveev et al. (2001) the wind direction was at least at the measurement station southerly on numerous days. Even if we assume, that air masses that crossed the evaporation ponds from the South towards the North do not reach the northern End of the lake but are redirected (e.g. due to the lake breeze) after reaching the centre of the lake (thus stopping our simulations after about $3 \mathrm{~h}$ or continuing them without further increasing the $\mathrm{pH}$ of the water) we can still conclude that we need a bromine source in addition to aerosols and that an ODE is likely to occur (fast) only under certain meteorological conditions.

The assumption that air masses reaching the South of the Dead Sea coming from the desert have a negligible halogen load might not be true under all circumstances. As was observed by Tas et al. (2005) air masses reaching the Dead Sea from the desert South of the lake can already contain a significant load of $\mathrm{BrO}$ (up to $20 \mathrm{pmol} / \mathrm{mol}$, Tas et al., 2005) which was attributed to recirculations of air masses. For such cases the Lagrangian setup underestimates initial halogen concentrations. However, the different simulations presented herein indicate that an additional halogen load of this reported order of magnitude would not lead to a much faster and much stronger $\mathrm{O}_{3}$ decrease than shown in the modelled cases.

\subsection{Aqueous phase reactions including DOM}

Halobromous oxide is likely to react efficiently with organic matter in the aqueous phase (e.g. Jaworske and Helz, 1985). One general uncertainty regarding our model results can be attributed to this reaction. A high uncertainty is related to the actual rate constant for the reaction between $\mathrm{HOBr}$ and $\mathrm{DOM}$ as well as to the DOM (or DOC) concentrations in the Dead Sea water. To the knowledge of the authors, the only values for DOM (and DOC) concentrations in the Dead Sea water are cited by Nissenbaum (1975) and are based on unpublished measurements. Therefore, we performed a series of sensitivity studies with different DOM concentrations and different rate coefficients in order to be able to discuss the potential impact of this reaction on our results.

No information is available about the sampling technique and analysis of the samples which were used to derive the DOM/DOC concentrations cited by Nissenbaum (1975). In addition the chemical composition of the Dead Sea water has changed over the last decades (Oren and Ventosa, 1999) as 
well as the salinity of the lake water (e.g. Anati and Shasha, 1989). Even though several microorganisms have been found in the Dead Sea water, their distribution does not seem to be homogeneous among the lake water and concentrations of bacteria seem to be comparatively low (Shimoni et al., 2002; Oren, 2008). Can we therefore also assume that DOM/DOC concentrations vary within the Dead Sea water, similar like the $\mathrm{pH}$ shows a gradient between the northern part of the lake and the southern part? Are there seasonal variations in DOM (or DOC) concentrations? We do not know where and when the samples were taken which were used for the creation of the dataset cited in Nissenbaum (1975). We further do not know if at that time e.g. algae were present in the lake water or had been present in the weeks before the sampling took place.

Implications for the model results: we varied DOM concentrations in the Dead Sea water between $0.0001 \mathrm{~g} / \mathrm{m}^{3}$ and $0.1 \mathrm{~g} / \mathrm{m}^{3}$ and the rate coefficient for the reaction between HOBr and DOM was varied between $10^{4}$ and $10^{6} \mathrm{M}^{-1} s^{-1}$ (based on Jaworske and Helz, 1985 and Pechtl et al., 2007, and references therein). If DOM concentrations exceed $0.01 \mathrm{~g} / \mathrm{m}^{3}, \mathrm{HOBr}$ concentrations in the Dead Sea water decrease almost immediately by about two orders of magnitude. This results in negligibly small mixing ratios of $\mathrm{BrO}$ in scenario EXALL whereas they still increase up to at least $15 \mathrm{pmol} / \mathrm{mol}$ (depending on the chosen rate coefficient) at $2 \mathrm{~m}$ altitude in scenario EXLIM. DOM concentrations for which at least several $\mathrm{pmol} / \mathrm{mol} \mathrm{BrO}$ build up in scenario EXLIM, are still smaller than reported in Nissenbaum (1975). Consequently, bromine species in the Dead Sea water become too small to degase in significant concentrations out of the Dead Sea water. Thus the question of additional bromine sources has to be addressed again. Surface reactions on the Dead Sea water could contribute to the gas phase bromine load as was suggested by Matveev et al. (2001) but they are considered to be of minor importance. Crystallized surface salt deposits were discussed as a potential bromine source. However, no striking correlations regarding the existence of such salt deposits and high $\mathrm{BrO}$ mixing ratios were observed and are reported in the literature. The sensitivity studies including reactions with DOM might further support the idea, that an inversion is necessary for the formation of high $\mathrm{BrO}$ levels (and an ODE).

We consider it as likely that DOM/DOC concentrations in the very shallow and highly concentrated evaporation ponds are lower than in the northern part of the Dead Sea which has a lower salinity. Thus concentrations of bromine species in the southern part of the lake would be high enough to degas into the atmosphere and supply a source for gas phase bromine species.

\subsection{Bromine source strength}

Apart from the uncertainties regarding the influence of meteorological background conditions on trace gas concentra- tions, one additional uncertainty is the actual source strength of bromine species degassing out of the Dead Sea water. As the evaporation ponds are very shallow, the water within the ponds have a highly concentrated bromide content and the depth of each pond is different and is varied regularly, the parameterisation used to calculate air-sea exchange might underestimate the bromine source strength over the evaporation ponds. However, it is difficult to estimate quantitatively how large this potential error might be.

In addition it is possible that bromine compounds are directly injected into the evaporation ponds by the Dead Sea Bromine Company during the process of industrial bromine production. These emissions into the water could contribute to the temporal as well as spacial variability of the bromine contend (depending on the emissions from the Dead Sea Works) in the different ponds at the southern end of the Dead Sea and thus to the varying bromine emission strength. This would also be an explanation for the highly variable $\mathrm{BrO}$ mixing ratios as observed over the evaporation ponds.

However, it is unlikely that the emissions by the Dead Sea Bromine Company are the only reason for the enhanced $\mathrm{BrO}$ mixing rations over the Dead Sea. Hebestreit et al. (1999) discuss the potential impact of gas phase emissions of the Dead Sea Works and point out that the diurnal variation of industrial emissions like $\mathrm{NO}_{\mathrm{x}}$ and $\mathrm{SO}_{2}$ are different than the diurnal variations of $\mathrm{BrO}$ concentrations. They even ruled out that the factory emissions are a bromine source due to the time variation of the $\mathrm{BrO}$ signal.

In order to test the effect of an additional bromine source over the Southern part of the Dead Sea, scenario ENH was calculated. $\mathrm{O}_{3}$ is depleted in this scenario even though more than $700 \mathrm{pmol} / \mathrm{mol} \mathrm{BrO}$ are formed. It was observed by Matveev et al. (2001) that ODEs can occur only affecting the Northern part of the Dead Sea like it is simulated in scenario ENH. Again it is not possible to evaluate the model results of scenario ENH and scenario LOWBL as well, regarding the vertical extent of the depletion event due to the lack of vertically resolved measurements.

As mentioned in the introduction a few measurements took place on an elevated site $400 \mathrm{~m}$ above water level. Only at 3 out of 22 days $\mathrm{BrO}(\approx 20 \mathrm{pmol} / \mathrm{mol})$ was detected and thus simulated values (EX, EXALL) are on the same order of magnitude at this altitude. Tas et al. (2003) assumed that on those three days where $\mathrm{BrO}$ mixing ratios were detected, the boundary layer height was very low. However, in scenario EXALL the boundary layer height is about $1300 \mathrm{~m}$ and $\mathrm{BrO}$ is transported very efficiently with high concentrations into altitudes around $400 \mathrm{~m}$. This let the question arise, what kind of local wind and transport pattern is responsible for the lack of $\mathrm{BrO}$ on the other days.

\subsection{Reactions on "dry" aerosol particles}

The main reason for the termination of aerosol chemistry in MISTRA is the low water content of aerosol particles 
due to the low ambient humidity. In order to enhance the recycling potential of halogens, scenarios NOEX and EXALL were calculated including heterogeneous reactions on dry aerosols based on several laboratory measurements (http: //jpldataeval.jpl.nasa.gov, Sander et al., 2006). Thus aerosol chemistry is calculated in all model layers and at all times. This setup leads to higher $\mathrm{BrO}$ mixing ratios due to the enhanced cycling potentials of halogen species. However, the enhancement of $\mathrm{BrO}$ formation by about $20 \%$ compared to scenario EXALL and by about $66 \%$ compared to scenario NOEX does (i) not lead to a stronger $\mathrm{O}_{3}$ destruction and (ii) in comparison to scenario NOEX the formation of $\mathrm{BrO}$ $\left(\mathrm{BrO}_{\max }: 0.02 \mathrm{pmol} / \mathrm{mol}\right)$ is still significantly lower than observations show. The slow phase transfer reactions due to the low ambient relative humidity and the low LWC is the main limitation for an efficient aerosol recycling of halogens.

\subsection{Literature comparison}

In general results from model simulations presented herein agree very well with a first simple model study by Stutz et al. (1999) who concluded that the production of $500 \mathrm{pmol} / \mathrm{mol}$ $\mathrm{BrO}$ would be essential to simulate a significant loss in $\mathrm{O}_{3}$ within at least three hours. However, results from both studies differ significantly from what is presented by Tas et al. (2006) and their follow up paper (Tas et al., 2008). Below we list the main differences in the model approaches used in this study and the study by Tas et al. (2006).

1. In their model calculations, Tas et al. (2006) consider aerosols as the only gas phase bromine source.

2. The model used by Tas et al. (2006) treats only gas phase chemistry explicitly, one aqueous phase and one heterogeneous reaction were parameterised.

3. The source strength of $\mathrm{Br}_{2}$ was not chosen process related by Tas et al. (2006) but was chosen until model simulations agreed best with observations.

4. The model simulations by Tas et al. (2006) were stronger constrained. $\mathrm{O}_{3}$ fluxes were prescribed into the model domain and consequently simulated and observed $\mathrm{O}_{3}$ concentrations agreed very well.

5. Tas et al. (2006) explain the fast decrease (as well as increase) in $\mathrm{O}_{3}$ concentrations by: "the decrease in $\mathrm{O}_{3}$ concentrations beneath a threshold value of $1-$ $2 \mathrm{nmol} / \mathrm{mol}$ acts as a motive force for fresh $\mathrm{O}_{3}$ fluxes to move into the evaporation ponds." whereas we consider either changes in the bromine source strength (see Sect. 8.3) or meteorological processes as the more likely explanation for the observations.

\section{Conclusions}

Regarding $\mathrm{O}_{3}$ depletion events at the Dead Sea, not only the strength of the $\mathrm{O}_{3}$ destruction but also the short timescale is striking. Additionally, the strong spatial and temporal variability of observed ODEs at the Dead Sea and the comparatively large range of corresponding $\mathrm{BrO}$ mixing ratios $(\approx 40$ $140 \mathrm{pmol} / \mathrm{mol}$ ) complicates the finding of an overall explanation of the occurring processes.

In general the model results presented herein clearly indicate that bromine release from salt aerosols is not sufficient as a source for $\mathrm{BrO}$ at the Dead Sea and that most likely air-sea exchange of halogens between the Dead Sea and the atmosphere has to be considered in order to simulate $\mathrm{BrO}$ mixing ratios in the same order of magnitude as observations show.

A fast and strong ODE could only be simulated if an inversion was assumed that limits vertical transport. In addition an ODE develops if either the flux of halogens out of the Dead Sea was temporally enhanced or if the BL height did not exceed $700 \mathrm{~m}$. In both cases however the time evolution of the ODE was much slower than often observed at the Dead Sea. It is difficult to evaluate the model results properly due to missing information regarding meteorological background conditions at the measurement days. In order to improve our understanding of $\mathrm{O}_{3}$ and halogen chemistry at the Dead Sea, the knowledge of temperature, relative humidity and the boundary layer height for every single measurement day is absolutely crucial.

It would be of interest to have a data set showing the vertical distribution of $\mathrm{BrO}$ and $\mathrm{O}_{3}$. Model simulations indicate that the vertical gradient in $\mathrm{BrO}$ mixing ratios is very strong in the lowest 10 to $20 \mathrm{~m}$ above the water surface. All published measurements were done with the DOAS technique at an altitude of approximately $2 \mathrm{~m}$. According to the model results it is even of significance whether measurements are taken at $1.50 \mathrm{~m}$ or $2.30 \mathrm{~m}$ or $10 \mathrm{~m}$. We have no reliable information regarding the vertical extent of an ODE and the strength of an ODE in the upper boundary layer. Overall it can be concluded that meteorological processes seem to play a key role in understanding the observed fast $\mathrm{O}_{3}$ depletion events. Chemical processes lead to the formation of $\mathrm{BrO}$ and the destruction of $\mathrm{O}_{3}$ however, the strength and spacial extent of the ODEs as well as the distribution of halogen species within the boundary layer strongly depend on the local meteorology.

Acknowledgements. This project was funded by the Deutsche Forschungsgemeinschaft DFG (Emmy Noether Junior Research Group MarHal GL 353/1-2) and is a contribution to the IGAC/SOLAS task "Halogens in the Troposphere".

The service charges for this open access publication have been covered by the Max Planck Society.

Edited by: A. Hofzumahaus 


\section{References}

Alpert, P., Shafir, H., and Issahary, D.: Recent changes in the climate at the Dead Sea - A Preliminary Study, Climate Change, 37, 513-537, 1997.

Anati, D. and Shasha, S.: Dead Sea surface-level changes, Isr. J. Earth Sci., 38, 29-32, 1989.

Barrie, L. A., Bottenheim, J. W., Schnell, R. C., Crutzen, P. J., and Rasmussen, R. A.: Ozone destruction and photochemical reactions at polar sunrise in the lower Arctic atmosphere, Nature, 334, 138-141, 1988.

Bitan, A.: The Influence of the Special Shape of the Dead-Sea and Its Environment on the Local Wind System, Arch. Meteor. Geophy. B, 24, 283-301, 1977.

Fickert, S., Adams, J. W., and Crowley, J. N.: Activation of $\mathrm{Br}_{2}$ and $\mathrm{BrCl}$ via uptake of $\mathrm{HOBr}$ onto aqueous salt solutions, J. Geophys. Res., 104, 23719-23727, 1999.

Hebestreit, K., Stutz, J., Rosen, D., Matveev, V., Peleg, M., Luria, M., and Platt, U.: DOAS Measurements of Tropospheric Bromine Oxide in Mid-Latitudes, Science, 283, 55-57, 1999.

Hönninger, G., Bobrowski, N., Palenque, E. R., Torrez, R., and Platt, U.: Reactive bromine and sulfur emissions at Salar de Uyuni, Bolivia, Geophys. Res. Lett., 31, L04101, doi:10.1029/2003GL018818, 2004.

Jaenicke, R.: Aerosol Physics and Chemistry, in: Landolt-Börnstein "Zahlenwerte und Funktionen aus Naturwissenschaften und Technik", V 4b, 391-457, Springer, 1988.

Jaworske, D. and Helz, G.: Rapid Consumption of Bromine Oxide in River and Estuarine Waters, Environ. Sci. Technol., 19, 11881191, 1985.

Kerkweg, A., Sander, R., Tost, H., Jöckel, P., and Lelieveld, J.: Technical Note: Simulation of detailed aerosol chemistry on the global scale using MECCA-AERO, Atmos. Chem. Phys., 7, 2973-2985, 2007,

http://www.atmos-chem-phys.net/7/2973/2007/.

Liss, P. S. and Slater, P. G.: Flux of Gases across the Air-Sea Interface, Nature, 147, 181-184, 1974.

Matveev, V., Peleg, M., Rosen, D., Tov-Alper, D. S., Hebestreit, K., Stutz, J., Platt, U., Blake, D., and Luria, M.: Bromine oxide - ozone interaction over the Dead Sea, J. Geophys. Res., 106, 10375-10387, 2001.

Monahan, E. C., Spiel, D. E., and Davidson, K. L.: A model of marine aerosol generation via whitecaps and wave disruption, in: Oceanic Whitecaps, edited by: Monahan, E. C. and Niocaill, G. M., D. Reidel, Norwell, Mass, 167-174, 1986.

Nissenbaum, A.: The Microbiology and Biogeochemistry of the Dead Sea, Microb. Ecol., 2, 139-161, 1975.

Oren, A.: Microbial life at high salt concentrations: phylogenetic and metabolic diversity, Saline Systems, 4(2), doi:10.11861/1746-1448-4-2, 2008.

Oren, A. and Ventosa, A.: Benjamin Elazari Volcani (1915-1999: Sixty-three years of studies of the microbiology of the Dead Sea), Int. Microbiol., 2, 195-198, 1999.

Pechtl, S., Schmitz, G., and von Glasow, R.: Modelling iodide iodate speciation in atmospheric aerosol: Contributions of inorganic and organic iodine chemistry, Atmos. Chem. Phys., 7, 1381-1393, 2007,

http://www.atmos-chem-phys.net/7/1381/2007/.

Pozzer, A., Jöckel, P., Sander, R., Williams, J., Ganzeveld, L., and Lelieveld, J.: Technical Note: The MESSy-submodel AIRSEA calculating the air-sea exchange of chemical species, Atmos. Chem. Phys., 6, 5435-5444, 2006,

http://www.atmos-chem-phys.net/6/5435/2006/.

Pruppacher, H. R. and Klett, J. D.: Microphysics of Clouds and Precipitation, Kluwer Academic Pub., Dordrecht/Boston/London, 1997.

Sander, S. P., Finlayson-Pitts, B. J., Friedl, R. R., Golden, D. M., Huie, R. E., Keller-Rudek, H., Kolb, C. E., Kurylo, M. J., Molina, M. J., Moortgat, G. K., Orkin, V. L., Ravishankara, A. R., and Wine, P. H.: Chemical Kinetics and Photochemical Data for Use in Atmoshperic Studies, JPL Publication 06-2, Jet Propulsion Laboratory, Pasadena, Evaluation Number 15, 2006.

Shimoni, M., Ben-Dor, E., Karnieli, A., Eichler, J., van der Meer, F., and Kaufmann, H.: Searching for Life in the Dead Sea: Microbiological Study Using Imaging Spectroscopy, Vol. 4545, in: Remote Sensing for Environmental Monitoring, GIS Applications, and Geology, edited by: Ehlers, M., Proceedings of SPIE, 155164, 2002.

Sirkes, Z., Schirmer, F., Essen, H.-H., and Gurgel, K.-W.: Surface currents and seiches in the Dead Sea, in: The Dead Sea: The Lake and Its Setting, edited by: Niemi, T., Ben-Avrahem, Z., and Gat, J., Oxford Monogr. Geol. Geophys., vol. 36, Oxford Univ. Press, New York, 104-113, 1997.

Stutz, J., Hebestreit, K., Alicke, B., and Platt, U.: Chemistry of Halogen Oxides in the Troposphere: Comparison of Model Calculations with Recent Field Data, J. Atmos. Chem., 34, 65-85, 1999.

Stutz, J., Ackermann, R., Fast, J. D., and Barrie, L.: Atmospheric Reactive Chlorine and Bromine at the Great Salt Lake, Utah, Geophys. Res. Lett., 29(10), 1380, doi:10.1029/2002GL014812, 2002.

Sverdrup, H., Johnson, M., and Fleming, R.: The Oceans, Their Physics, Chemistry and General Biology, Prentice-Hall, Englewood Cliffs, NJ, USA, 1942.

Tang, I.: Thermodynamic and optical properties of mixed-salt aerosols of atmospheric interest, J. Geophys. Res., 102, 18831893, 1997.

Tas, E., Matveeva, V., Zingler, J., Luria, M., and Peleg, M.: Frequency and extent of ozone destruction episodes over the Dead Sea, Israel, Atmos. Environ., 37, 4769-4780, 2003.

Tas, E., Peleg, M., Matveev, V., Zingler, J., and Luria, M.: Frequency and extent of bromine oxide formation over the Dead Sea, J. Geophys. Res., 110, D11304, doi:10.1029/2004JD005665, 2005.

Tas, E., Peleg, M., Pedersen, D. U., Matveev, V., Pour Biazar, A., and Luria, M.: Measurement-based modeling of bromine chemistry in the boundary layer: 1 . Bromine chemistry at the Dead Sea, Atmos. Chem. Phys., 6, 5589-5604, 2006, http://www.atmos-chem-phys.net/6/5589/2006/.

Tas, E., Peleg, M., Pedersen, D. U., Matveev, V., Biazar, A. P., and Luria, M.: Measurement-based modeling of bromine chemistry in the Dead Sea boundary layer - Part 2: The influence of $\mathrm{NO}_{2}$ on bromine chemistry at mid-latitude areas, Atmos. Chem. Phys., 8, 4811-4821, 2008, http://www.atmos-chem-phys.net/8/4811/2008/.

Vogt, R., Crutzen, P. J., and Sander, R.: A mechanism for halogen release from sea-salt aerosol in the remote marine boundary layer, Nature, 383, 327-330, 1996.

von Glasow, R. and Crutzen, P.: Troposheric Halogen Chemistry, 
Vol. 4.02, in: Treatise on Geochemistry Update 1, edited by: Holland, H. D. and Turekian, K. K., Elsevier-Pergamon, Oxford, 1-67, 2007.

von Glasow, R., Sander, R., Bott, A., and Crutzen, P.: Modeling halogen chemistry in the marine boundary layer 1 . Cloud-free MBL, J. Geophys. Res., 107, 4341, doi:10.1029/2001JD000942, 2002a. von Glasow, R., Sander, R., Bott, A., and Crutzen, P. J.: Modeling halogen chemistry in the marine boudary layer 2. Interactions with sulfur and cloud-covered MBL, J. Geophys. Res., 107, 4323, doi:10.1029/2001JD000943, 2002b.

Zingler, J. and Platt, U.: Iodine oxide in the Dead Sea Valley: Evidence for inorganic sources of boundary layer IO, J. Geophys. Res., 110, D07307, doi:10.1029/2004JD004993, 2005. 